Research brief

\title{
Trypanosoma cruzi: Sensitivity of the polymerase chain reaction for detecting the parasite in the blood of mice infected with different clonal genotypes
}

\author{
C.T. Miyamoto a , M.L. Gomes ${ }^{\text {a }}$, A.V. Marangon ${ }^{\text {a }}$, S.M. Araújo a, \\ M.T. Bahia ${ }^{c}$, M. Lana ${ }^{b}$, M.J.O. Toledo ${ }^{\mathrm{a}, *}$ \\ ${ }^{a}$ Departamento de Análises Clínicas, Laboratório de Parasitologia Básica, Bloco I-90, Universidade Estadual de Maringá, \\ Av. Colombo 5790, 87020-900, C.P. 331, Maringá, Paraná, Brazil \\ ${ }^{\mathrm{b}}$ Departamento de Análises Clínicas, Escola de Farmácia, Rua Costa Sena, 171, Universidade Federal de Ouro Preto (UFOP), \\ 35400-000 Ouro Preto, Minas Gerais (MG), Brazil \\ ${ }^{\mathrm{c}}$ Departamento de Ciências Biológicas, Instituto de Ciências Exatas e Biológicas, Campus Universitário Morro do Cruzeiro, \\ UFOP, 35400-000 Ouro Preto, MG, Brazil
}

Received 22 February 2005; received in revised form 25 October 2005; accepted 27 October 2005

Available online 22 December 2005

\begin{abstract}
The polymerase chain reaction showed high sensitivity for detecting Trypanosoma cruzi in the blood of mice, independent of clonal genotype (19, 20-T. cruzi I; 32, 39-T. cruzi II) or phase of the infection (acute or chronic).
\end{abstract}

(C) 2005 Elsevier Inc. All rights reserved.

Index Descriptors and Abbreviations: Trypanosoma cruzi; Mice; Genotypes; PCR, Polymerase chain reaction

Natural populations of Trypanosoma cruzi, the agent of Chagas' disease or American trypanosomiasis, show a long-term clonal evolution, thereby allowing genetic recombination events (Gaunt et al., 2003; Tibayrenc et al., 1986). This species is divided into two main phylogenetic lineages: T. cruzi I and T. cruzi II (Anonymous, 1999). According to the proposed nomenclature, genotypes 19 and 20 of $T$. cruzi, described previously by Tibayrenc et al. (1986), are included in the T. cruzi I group, and genotypes 32 and 39 in the $T$. cruzi II group. These clonal genotypes illustrate different phylogenetic relationships. Genotypes 19 and 20 are very closely related to each other and genetically distant from genotypes 32 and 39, which are also mutually closely related. Several investigators have verified experimentally a significant association between genetic distance and biological differences, both in vitro (Revollo et al., 1998) and

\footnotetext{
* Corresponding author. Fax: +55 21442614490.

E-mail address: mjotoledo@uem.br (M.J.O. Toledo).
}

in vivo (Toledo et al., 2002). These results have demonstrated the importance of considering the phylogenetic diversity of natural clones of $T$. cruzi in applied studies relating to the diagnosis, drug design, and clinical diversity of Chagas' disease.

Trypanosoma cruzi infection can be diagnosed by demonstrating the presence of the parasite by direct and indirect parasitological methods, immunodiagnosis being used to detect specific antibodies against $T$. cruzi, or by molecular methods that search for parasite DNA. Among the molecular methods of diagnosis is the polymerase chain reaction (PCR), which shows varying levels of sensitivity $(44.6-100 \%)$ in humans (Ávila et al., 1993; Britto et al., 1995; Castro et al., 2002; Gomes et al., 1998). This variation may result from, among other factors, genetic differences in the parasite (Portela-Lindoso and Shikanai-Yasuda, 2003) and the protocol used (Gomes et al., 1998).

Previously, we demonstrated in mice that the positivity of fresh blood examination, hemoculture, and ELISA would vary depending on the genotype of $T$. cruzi 
(Toledo, 2001; Toledo et al., 2002). The objective of the present study was to evaluate the sensitivity of PCR in detecting DNA of $T$. cruzi in the blood of mice infected with the different clonal genotypes, in both the acute and chronic phases of infection.

The blood samples tested in the present study were obtained from BALB/c mice experimentally infected with $20 \mathrm{~T}$. cruzi cloned stocks belonging to the 4 major genotypes (19, 20, 32, and 39) (Tibayrenc et al., 1986). Five stocks belonging to each genotype were used (Toledo et al., 2002). Groups of 10 female BALB/c mice, $18 \mathrm{~g}$ of body weight, were inoculated intraperitoneally with a standard inoculum of 10,000 blood trypomastigotes per animal of each stock.

For fresh blood examination (FBE), $5 \mu \mathrm{L}$ blood collected from the tail vein was examined daily during the acute phase, until 90 days after infection (d.a.i.). Hemoculture (HC) was carried out according to the technique of Filardi and Brener (1987). Briefly, approximately $0.4 \mathrm{~mL}$ blood collected aseptically from the retro-orbital sinus vein, in the acute phase (AP-60 d.a.i.) and during the chronic phase ( $\mathrm{CP}-140$ d.a.i.) of infection, was distributed into two tubes, each containing $3 \mathrm{~mL}$ LIT medium. These tubes were incubated at $28^{\circ} \mathrm{C}$ and examined after $30,45,60$, and 90 days. HC was also employed to confirm the infection of the animals that showed a negative FBE (subpatent parasitemia). An enzyme-linked immunosorbent assay (ELISA) modified according to Voller et al. (1980) was used. Alkaline antigen of the T. cruzi Y strain obtained in the exponential growth phase in LIT medium, and peroxidase-labeled anti-mouse immunoglobulin $G$ conjugated (Sigma) were used. Samples of serum collected in the early chronic phase (120 d.a.i.) and in the late chronic phase (290 d.a.i.) and diluted to 1:40 in phosphate-buffered saline, were used. The mean absorbance for 10 negative-control serum samples plus 2 standard deviations was used as the cut-off to discriminate positive and negative results.
For PCR, 131 blood samples were obtained, 70 in the AP and 61 in the $\mathrm{CP}$ of infection, at the same time that $\mathrm{HC}$ was carried out. Two hundred microliters of blood from each animal was added to double the volume of $6.0 \mathrm{M} / 0.2 \mathrm{M}$ guanidine/EDTA and stored at room temperature (Ávila et al., 1991). The lysate was boiled for $7 \mathrm{~min}$ (Britto et al., 1993) and the DNA extraction carried out in an aliquot of $100 \mu \mathrm{L}$ using the Wincker et al. (1994) protocol as modified by Gomes et al. (1998). The DNA solution was then washed with $70 \%$ ethanol prior to precipitation in order to remove potential PCR inhibitors. Finally, the DNA was resuspended in $10 \mu \mathrm{L}$ $\mathrm{H}_{2} \mathrm{O}$ MiliQ. During this stage, one negative and one positive control were added to each group of 4 samples. PCR amplification was performed in a total volume of $10 \mu \mathrm{L}$ according to Gomes et al. (1998), using 121 (5'-AAATAATGT ACGGG(T/G)GAGATGCATGA-3') and 122 (5'-GGTT CGATTGGGGTTGGTGTAATATA-3') primers to amplify a specific fragment of 330 base pairs (bp) of kinetoplast DNA (kDNA) of $T$. cruzi. The reaction mixture was submitted to 35 amplification cycles in a thermocycler (MJ Research, PTC-150), using $95^{\circ} \mathrm{C}$ for $1 \mathrm{~min}$ for denaturation with a longer initial time of $5 \mathrm{~min}, 65^{\circ} \mathrm{C}$ for $1 \mathrm{~min}$ for primer annealing, and $72^{\circ} \mathrm{C}$ for $1 \mathrm{~min}$ for extension with a final incubation at $72^{\circ} \mathrm{C}$ for $10 \mathrm{~min}$. In this step, as a contamination control, two negative and two positive controls from the extraction step were added to every 8 samples, and one negative and one positive control to the PCR. All the stages were carried out in separate environments with reagents, materials, and equipment exclusive to each area. The PCR products were visualized in $4.5 \%$ polyacrylamide silver-stained gel. For statistical analysis, the PCR positivity among the genotypes and phases of infection was compared by Chi-squared $\left(\chi^{2}\right)$ test with the software Statistica version 6.0 (StatSoft, Inc., 2001).

The positivity of FBE, HC, and ELISA tests varied according to the T. cruzi genotype and not the PCR (Table 1). Significant differences were observed for FBE between genotypes 20 and $39(p<0.01)$ and 20 and $32(p<0.001)$, for

Table 1

Results of the PCR, FBE, HC, and ELISA in blood samples of BALB/c mice infected with T. cruzi cloned stocks belonging to genotypes 19, 20, 32, and 39, in the acute and chronic phases of infection

\begin{tabular}{|c|c|c|c|c|c|}
\hline Genotypes & Phase & No. + FBE (\%) & No. + HC (\%) & No. + ELISA (\%) & No. + PCR (\%) \\
\hline 19 & Acute & $19 / 25(76.00)$ & $6 / 8(75.00)$ & $13 / 13(100.00)$ & $12 / 12(100.00)$ \\
\hline 19 & Chronic & - & $11 / 11(100.00)$ & $7 / 7(100.00)$ & $13 / 13(100.00)$ \\
\hline Total 19 & & $19 / 25(76.00)$ & $17 / 19(89.47)$ & $20 / 20(100.00)$ & $25 / 25(100.00)$ \\
\hline 20 & Acute & $37 / 41(90.24)$ & $22 / 23(95.65)$ & $22 / 22(100.00)$ & $23 / 23(100.00)$ \\
\hline 20 & Chronic & - & $15 / 18(83.33)$ & $17 / 17(100.00)$ & $18 / 18(100.00)$ \\
\hline Total 20 & & $37 / 41(90.24)$ & $37 / 41(90.24)$ & $39 / 39(100.00)$ & $41 / 41(100.00)$ \\
\hline 32 & Acute & $17 / 30(56.66)$ & $10 / 14(71.42)$ & $9 / 10(90.00)$ & $14 / 14(100.00)$ \\
\hline 32 & Chronic & - & $13 / 16(81.25)$ & $10 / 12(83.33)$ & $16 / 16(100.00)$ \\
\hline Total 32 & & $17 / 30(56.66)$ & $23 / 30(76.66)$ & $19 / 22(86.36)$ & $30 / 30(100.00)$ \\
\hline 39 & Acute & $23 / 35(65.71)$ & $14 / 19(73.68)$ & $14 / 15(93.33)$ & $20 / 20(100.00)$ \\
\hline 39 & Chronic & - & $6 / 14(42.85)$ & $10 / 12(83.33)$ & $15 / 15(100.00)$ \\
\hline Total 39 & & $23 / 35(65.71)$ & $20 / 33(60.60)$ & $24 / 27(88.88)$ & $35 / 35(100.00)$ \\
\hline Total & & $96 / 131(73.28)$ & $97 / 123(78.86)$ & $102 / 108(94.44)$ & $131 / 131(100.00)$ \\
\hline
\end{tabular}

No. + PCR, FBE, HC, and ELISA = number of positive mice of total analyzed. 
HC between genotypes 19 and $39(p<0.05)$ and 20 and 39 $(p<0.01)$, and for ELISA between genotypes 20 and 32 $(p<0.05)$, independent of the phase of infection (Table 2). The positivity of $\mathrm{HC}$ was significantly different only during the $\mathrm{CP}$ and between $19 \times 39(p<0.01), 20 \times 39$, and $39 \times 32$ $(p<0.05)$ (Table 2). There were no significant differences in the $\%+\mathrm{HC}, \%+$ ELISA, and $\%+\mathrm{PCR}$ of the AP in relation to the $\mathrm{CP}$ for animals infected with the four genotypes.

The PCR positivity $(100 \%)$ was significantly higher than that of the other techniques (data not shown). This result obtained in mice confirms data from other investigators showing that PCR is the best method to detect $T$. cruzi in

Table 2

Statistical comparisons of genotypes 19, 20, 32, and 39 for the different techniques used in the diagnosis of mice experimentally infected with $T$. cruzi cloned stocks in the acute and chronic phases of infection

\begin{tabular}{lllllll}
\hline Parameter & $19 \times 20$ & $19 \times 39$ & $19 \times 32$ & $20 \times 39$ & $20 \times 32$ & $39 \times 32$ \\
\hline FBE (Total) & NS & NS & NS & $<0.01$ & $<0.001$ & NS \\
HC (Total) & NS & $<0.05$ & NS & $<0.01$ & NS & NS \\
HC (AP) & NS & NS & NS & NS & NS & NS \\
HC (CP) & NS & $<0.01$ & NS & $<0.05$ & NS & $<0.05$ \\
ELISA (Total) & NS & NS & NS & NS & $<0.05$ & NS \\
ELISA (AP) & NS & NS & NS & NS & NS & NS \\
ELISA (CP) & NS & NS & NS & NS & NS & NS \\
PCR (Total) & NS & NS & NS & NS & NS & NS \\
PCR (AP) & NS & NS & NS & NS & NS & NS \\
PCR (CP) & NS & NS & NS & NS & NS & NS \\
\hline
\end{tabular}

Chi-squared test $\left(\chi^{2}\right)$; NS, not significant; $p \leqslant 0.05$ (significant difference). $\mathrm{AP}$, acute phase; $\mathrm{CP}$, chronic phase. human and dog blood (Araújo et al., 2002; Ávila et al., 1993; Britto et al., 1995; Castro et al., 2002; Gomes et al., 1998).

When a $100 \%$ positivity is observed, the first question that arises is whether contamination had occurred during the process. However, as described previously, the PCR steps were carried out in separate rooms and carefully controlled by the use of negative and positive controls in a systematic way. Therefore, the possibility that these results are due to contamination that could generate false positive results can be excluded.

Although there are few studies using PCR in murine models, the increased positivity of PCR in mice infected with different genotypes of $T$. cruzi obtained in the present study contrasts with the results of Camandaroba et al. (2003). These authors observed, in agarose gel, a PCR positivity of only $40 \%$ in mice infected with the Colombian strain and with its respective clones ( $T$. cruzi I), even when starting from a larger blood sample volume $(500 \mu \mathrm{L})$ than was used in the present study $(200 \mu \mathrm{L})$. A possible explanation for this difference is the protocol for extraction, amplification, and visualization of amplified products used in this study in relation to that used by Camandaroba et al. (2003). Although ethidium bromide-stained agarose electrophoresis is commonly used to detect $T$. cruzi DNA, in this work the amplified products were visualized in polyacrylamide gel according to the protocol of Gomes et al. (1998).

In relation to the genetic diversity of the parasite, the single difference in the PCR results was the presence of weaker bands in the gel for some stocks from genotypes 32

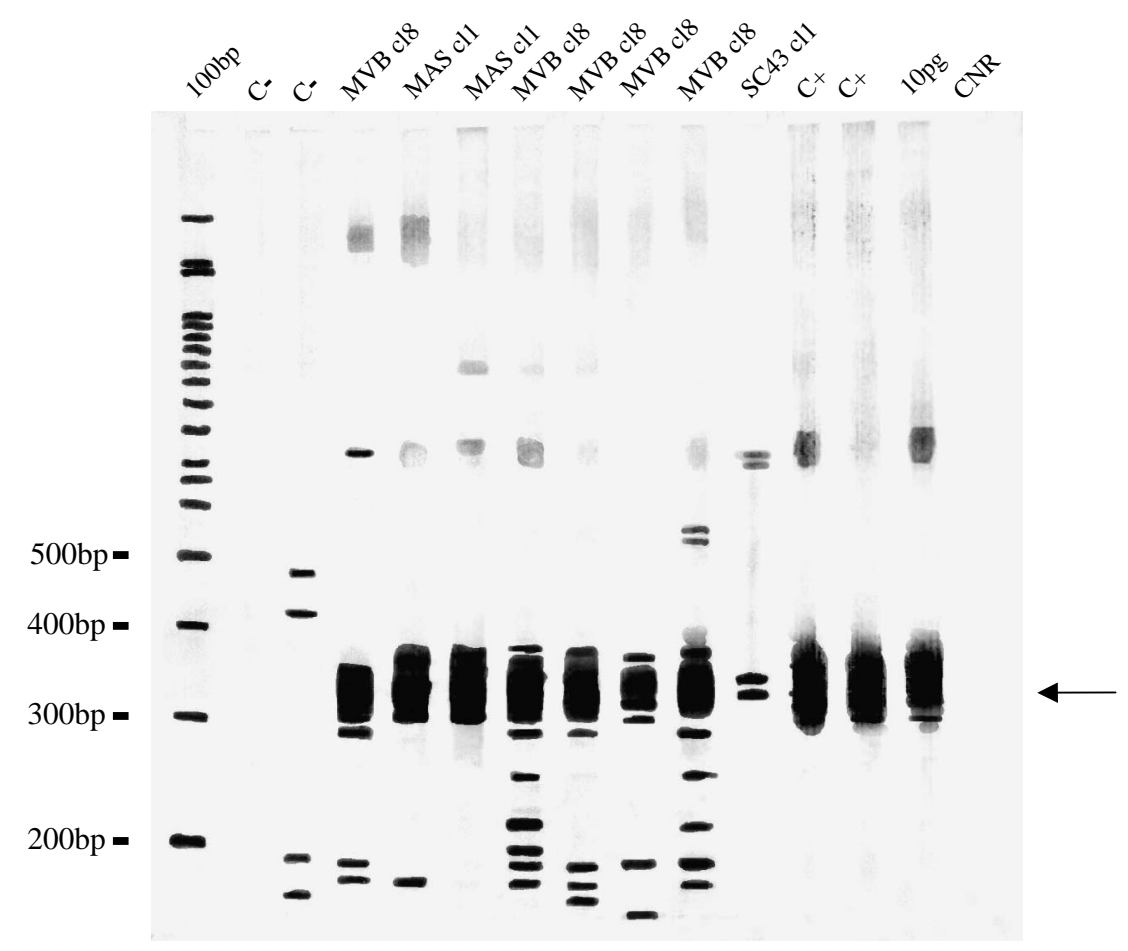

Fig. 1. Polyacrylamide gel showing specific products of $330 \mathrm{bp}$ (indicated by arrow) of the minicircle of the kDNA of $T$. cruzi in the blood of mice infected with cloned stocks of the genotypes 39 (SC43 cl1) and 32 (MAS cll and MVB cl8). $100 \mathrm{bp}$, molecular marker DNA ladder; C-, DNA from blood of noninfected mice; C+, DNA from blood of mice infected with the Y strain of T. cruzi; $10 \mathrm{pg}$, the positive control for PCR (DNA from T. cruzi strain 379 ); CNR, no DNA in the reaction mixture for the PCR amplification; bp, base pairs. 
and 39 (T. cruzi II). This result is shown in Fig. 1 (lane 11). Interestingly, mice infected with stocks pertaining to these genotypes (SC43 cl1 and MVB cl8) displayed subpatent parasitemia (Toledo, 2001). These results agree with those obtained by Virreira et al. (2003), who observed that the intensity of the DNA bands may vary according to the genetic lineage of $T$. cruzi, when the amplification was carried out with different primers, among them, 121 and 122 which were used in the present study.

The high PCR positivity, independent of the clonal genotype and phase of infection, confirms previous results using this methodology as a diagnostic tool for detection of T. cruzi DNA in blood of different host species. PCR has a direct application as a confirmatory method in situations with dubious serological evidence, and to evaluate the efficacy of the etiological treatment of $T$. cruzi infection.

\section{Acknowledgment}

To Michel Tibayrenc of the Centre d'Études sur le Polymorphisme des Microorganismes of the Institute de Recherche pour le Développement (IRD), Montpellier, France, for providing the cloned stocks of Trypanosoma cruzi.

\section{References}

Anonymous, 1999. International Symposium to commemorate the 90th anniversary of the discovery of Chagas disease. Recommendations from a Satellite Meeting, Rio de Janeiro, Brazil. Memórias do Instituto Oswaldo Cruz 94 (Suppl. I), pp. 429-432.

Araújo, F.M.G., Bahia, M.T., Magalhães, N.M., Martins-Filho, O.A., Veloso, V.M., Carneiro, C.M., Tafuri, W.L., Lana, M., 2002. Follow-up of experimental chronic Chagas' disease in dogs: use of polymerase chain reaction (PCR) compared with parasitological and serological methods. Acta Tropica 81, 21-31.

Ávila, H.A., Sigman, D., Cohen, L., Millikan, R., Simpson, L., 1991. Polymerase chain reaction of Trypanosoma cruzi kinetoplast minicircle DNA isolated from whole blood lysate: diagnosis of chronic Chagas' disease. Molecular and Biochemical Parasitology 48, 211-222.

Ávila, H.A., Pereira, J.B., Thiemann, O., Paiva, E., Degrave, W., Morel, C.M., Simpson, L., 1993. Detection of Trypanosoma cruzi in blood specimens of chronic chagasic patients by polymerase chain reaction amplification of kinetoplast minicircle DNA: comparison with serology and xenodiagnosis. Journal of Clinical Microbiology 31, 24212426.

Britto, C., Cardoso, M.A., Wincker, P., Morel, C.K., 1993. A simple protocol for the physical cleavage of Trypanosoma cruzi kinetoplast DNA present in blood samples and its use in polymerase chain reaction (PCR)-based diagnosis of chronic Chagas disease. Memórias do Instituto Oswaldo Cruz 88, 171-172.

Britto, C., Cardoso, M.A., Vanni, C., Hasslocker-Moreno, A., Xavier, S., Oeleman, W., Santoro, A., Pimez, C., Morel, C.M., Wincker, P., 1995.
Polymerase chain reaction detection of Trypanosoma cruzi in human blood samples as a tool for diagnosis and treatment evolution. Parasitology 110, 241-247.

Camandaroba, E.L.P., Reis, E.A.G., Gonçalves, M.S., Reis, M.G., Andrade, S.G., 2003. Trypanosoma cruzi: susceptibility to chemotherapy with benznidazole of clones isolated from the highly resistant Colombian strain. Revista da Sociedade Brasileira de Medicina Tropical 36 (2), 201-209.

Castro, A.M., Luquetti, A.O., Rassi, A., Rassi, G.G., Chiari, E., Galvão, L.M., 2002. Blood culture and polymerase chain reaction for the diagnosis of the chronic phase of human infection with Trypanosoma cruzi. Parasitology Research 88 (10), 894-900.

Filardi, L.S., Brener, Z., 1987. Susceptibility and natural resistance of Trypanosoma cruzi strains to drugs used clinically in Chagas disease. Transactions of the Royal Society of Tropical Medicine and Hygiene 81, 755-759.

Gaunt, M.W., Yeo, M., Frame, I.A., Stothard, J.R, Carrasco, H.J., Taylor, M.C., Mena, S.S., Veazey, P., Miles, G.A., Acosta, N., De Arias, A.R., Miles, M.A., 2003. Mechanism of genetic exchange in American trypanosomes. Nature 421 (6926), 936-939.

Gomes, M.L., Macedo, A.M., Vago, R., Pena, S.D.J., Galvão, L.M.C., Chiari, E., 1998. Trypanosoma cruzi: optimization of polymerase chain reaction for detection in human blood. Experimental Parasitology 88, 28-33.

Portela-Lindoso, A.A.B., Shikanai-Yasuda, M.A., 2003. Doença de Chagas crônica: do xenodiagnóstico e hemocultura à reação em cadeia da polimerase. Revista de Saúde Pública 37 (1), 107-115.

Revollo, S., Oury, B., Laurent, J.P., Barnabé, C., Quesney, V., Carriére, V., Noël, S., Tibayrenc, M., 1998. Trypanosoma cruzi: impact of clonal evolution of the parasite on its biological and medical properties. Experimental Parasitology 89, 30-39.

StatSoft, Inc., 2001. Statistica (data analysis software system), version 6. www.statsoft.com.

Tibayrenc, M., Ward, P., Moya, A., Ayala, F.J., 1986. Natural populations of Trypanosoma cruzi, the agent of Chagas disease, have a complex multiclonal structure. Proceedings of the National Academy of Sciences of the United States of America 83, 115-119.

Toledo, M.J.O., 2001. Comportamento biológico em camundongos de clones de Trypanosoma cruzi pertencentes a diferentes genótipos. Doctoral Thesis, Universidade Federal de Minas Gerais-Belo Horizonte, MG, Brazil.

Toledo, M.J.O, Lana, M., Carneiro, C.M., Bahia, M.T., Machado-Coelho, G.L.L., Veloso, V.M., Barnabé, C., Tibayrenc, M., Tafuri, W.L., 2002. Impact of Trypanosoma cruzi clonal evolution on its biological properties in mice. Experimental Parasitology 100, 161-172.

Virreira, M., Torrico, F., Truyens, C., Alonso-Veja, C., Solano, M., Carlier, Y., Svoboda, M., 2003. Comparison of polymerase chain reaction methods for reliable and easy detection of congenital Trypanosoma cruzi infection. American Journal of Tropical Medicine and Hygiene 68 (5), 574-582.

Voller, A., Bidwell, D., Bartlet, A., 1980. Enzyme linked immunosorbent assay. In: Rose, N.R., Friedman, R. (Eds.), Manual of Clinical Immunology. American Society for Microbiology, USA, pp. 359-371.

Wincker, P., Britto, C., Pereira, J.B., Cardoso, M.A., Oelemann, W., Morel, C.M., 1994. Use of a simplified polymerase chain reaction procedure to detect Trypanosoma cruzi in blood samples from patients in a rural endemic area. American Journal of Tropical Medicine and Hygiene 51, 771-777. 